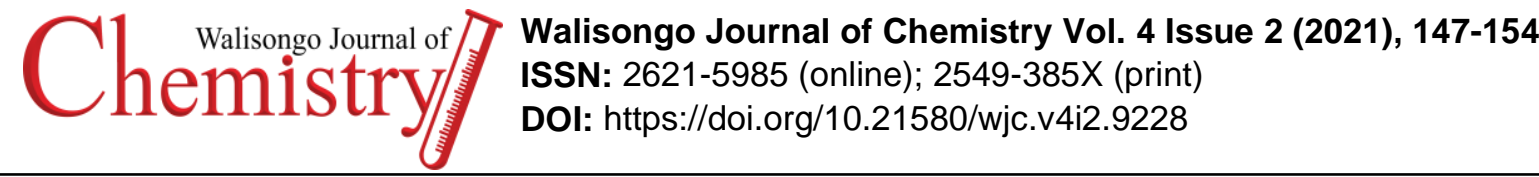

\section{Toward Novel Antioxidant Drugs: Quantitative Structure-Activity Relationship Study of Eugenol Derivatives}

\author{
Priyagung Dhemi Widiakongko*, Karisma Triatmaja \\ Universitas Islam Negeri Sunan Kalijaga, Yogyakarta, Indonesia \\ *E-mail: priyagung.widiakongko@uin-suka.ac.id
}

Received: 15 September 2021; Accepted: 15 November 2021; Published: 15 December 2021

\begin{abstract}
The study of the Quantitative Structure-Activity Relationship (QSAR) of eugenol compound and its derivatives towards antioxidant activities was conducted using electronic and molecular descriptors. These descriptors were generated from semi-empirical chemical computation with PM3 level of theory. The QSAR model in this research could be used to predict novel antioxidant compounds which are more potent. The activity of the compound determined based on the IC $C_{50}$ value (Inhibition Concentration 50\%) was linked with the descriptor results that had been calculated in a QSAR equation. The data showed that the descriptors that had a significant effect were a net charge of $C-6, C-7,0-12$, and HOMO energy and hydration energy. The best QSAR equations obtained with these descriptors and their parameters are shown as follows.

$$
\begin{gathered}
\log 1 / I C_{50}=-3,3026( \pm 0,4066) q C 6-4,7450( \pm 0,7224) q C 7+3,2746( \pm 0,6752) q 012+0,6326( \pm \\
0,0645) \text { HOMO }-0,0086( \pm 0,0011) \text { hydration energy }+4,8053( \pm 0,6336) \\
(n=8 ; R=1,000 ; s=0,004 ; F=3655,537 ; p=0,0003 ; Q 2=0,988 ; \text { SPress }=0,039 ; \text { SDEP }=0,021)
\end{gathered}
$$
\end{abstract}

Keywords: QSAR analysis; Eugenol Derivatives; Antioxidant Activity; Novel Antioxidant drugs

\section{Introduction}

The antioxidant is a compound that can inhibit oxidation reactions through radical scavenging (Amanda et al., 2019). This compound can be found as natural ingredients such as flavonoid groups (Arifin \& Ibrahim, 2018), saponins and phenolic groups (Hanifa \& Susilawati, 2017), and also synthetic drug compounds (Ribaudo et al., 2020). Antioxidant compounds play a key role in maintaining brain function through oxygen radical scavenging mechanisms (Ribaudo et al., 2020). Several antioxidant compounds from natural ingredients have been reported to have good activity, such as the extract of gandaria fruit and gandaria seeds which have $\mathrm{IC}_{50}$ values of $36,3 \mathrm{~g} / \mathrm{mL}$ and 7,25 g/mL (Hanifa \& Susilawati, 2017). Likewise, synthetic antioxidant drug compounds have also been reported to have better activity than vitamin C. Despite these advantages, however, there are several significant side effects reported in the consumption of synthetic antioxidant drug compounds including agranulocytosis and hepatotoxicity effects (Ribaudo et al., 2020). Thus, the development of medicinal compounds with antioxidant activity from natural ingredients needs to be carried out on an ongoing basis. These development efforts are carried out by modifying compounds to increase the activity of these 
natural ingredients so that they can be more accepted by the body (Hussain et al., 2017).

One of the natural compounds which contain antioxidant activity is eugenol (da Silva et al., 2018). It is a natural compound extracted from clove leaves. Eugenol has a benzene ring core structure which is substituted by hydroxy, methoxy, and allyl groups at positions 1, 2, and 4, respectively ( Sohilait \& Kainama, 2019). The phenolic framework in eugenol allows these compounds to have antioxidant activity by releasing 1 electron to radicals and converting radicals into less reactive molecules (Amanda et al., 2019). The antioxidant activity of eugenol has been reported in $\mathrm{IC}_{50}$ values against $\mathrm{DPPH}$. The $\mathrm{IC}_{50}$ value of eugenol is $10,290,011 \mathrm{~g} / \mathrm{mL}$, close to the $\mathrm{IC}_{50}$ value of ascorbic acid, which is $8,580,0009 \mathrm{~g} / \mathrm{mL}$. In addition, there are several compounds derived from eugenol which are reported to have a lower $\mathrm{IC}_{50}$ value than eugenol (Dhiman et al., 2019). These data indicate that the antioxidant drug compound of eugenol and its derivatives can be explored further to obtain an antioxidant drug compound that is more potent than ascorbic acid.

The equations generated by the QSAR method can have several models of combination descriptors that are analyzed statistically. Several descriptors that are often used in QSAR follow the Hansch model, namely electronic descriptors, topologic descriptors, and lipophilic descriptors (Cortes et al., 2020). The validation used is the R-value, standard deviation, and a significant F-value (Mumpuni \& Mulatsari, 2017). The equation model with an $R 2$ value close to 1 is the equation model chosen because it is compatible with the experimental data. This equation can be used to predict new drug compounds that are more potent by inserting the structure descriptor of the predicted compound into the equation.

This study aims to find the best QSAR equation model for the series of eugenol compounds and their derivatives on antioxidant activity using experimental data from previous studies (Dhiman et al., 2019). Furthermore, the equation is used to predict new drug compounds from eugenol derivatives which are expected to have a lower $\mathrm{IC}_{50}$ value than compounds that have been synthesized previously. The design of the new compound became the basis for the synthesis of eugenol derivatives with better antioxidant activity.

\section{Methodology}

Research Materials

The data set used in this study is shown in Table 1 . These are taken from previous experimental studies (Dhiman et al., 2019). Table 1 contains the structure and activity data of eugenol \& its derivatives. The structure of eugenol is shown in figure 1 and the modified structure of eugenol is shown in figure 2 .

\section{Equipment}

The hardware used is a set of computers with AMD Ryzen $51.4 \mathrm{GHz}$ processor, AMD Radeon Graphics, and $8 \mathrm{~Gb}$ RAM (Random Access Memory). The software used is Hyperchem Professional version 8.0 and this is used to perform chemical descriptor calculations and buildQSAR (De Oliveira \& Gaudio, 2001) to perform statistical analysis.

Procedure

Each compound in Table 1. is presented as a 2D structure and then we conducted geometric optimization using the PM3 semi-empirical method with the PolakRibiere algorithm and boundaries RMS gradient (root mean square) $0,01 \mathrm{kcal} /(\AA$ mol). All geometry optimization procedures were performed using Hyperchem.

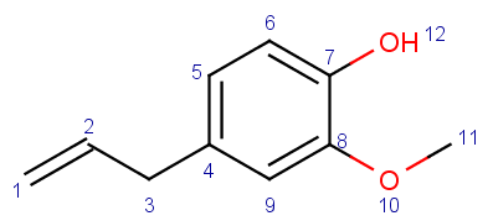

Figure 1. Eugenol Structure 
<smiles>[R]Oc1ccc(CC=C)cc1OC</smiles>

Figure 2. Modified structure of the eugenol derivative

Table 1. Visualization of the activity of Eugenol derivatives

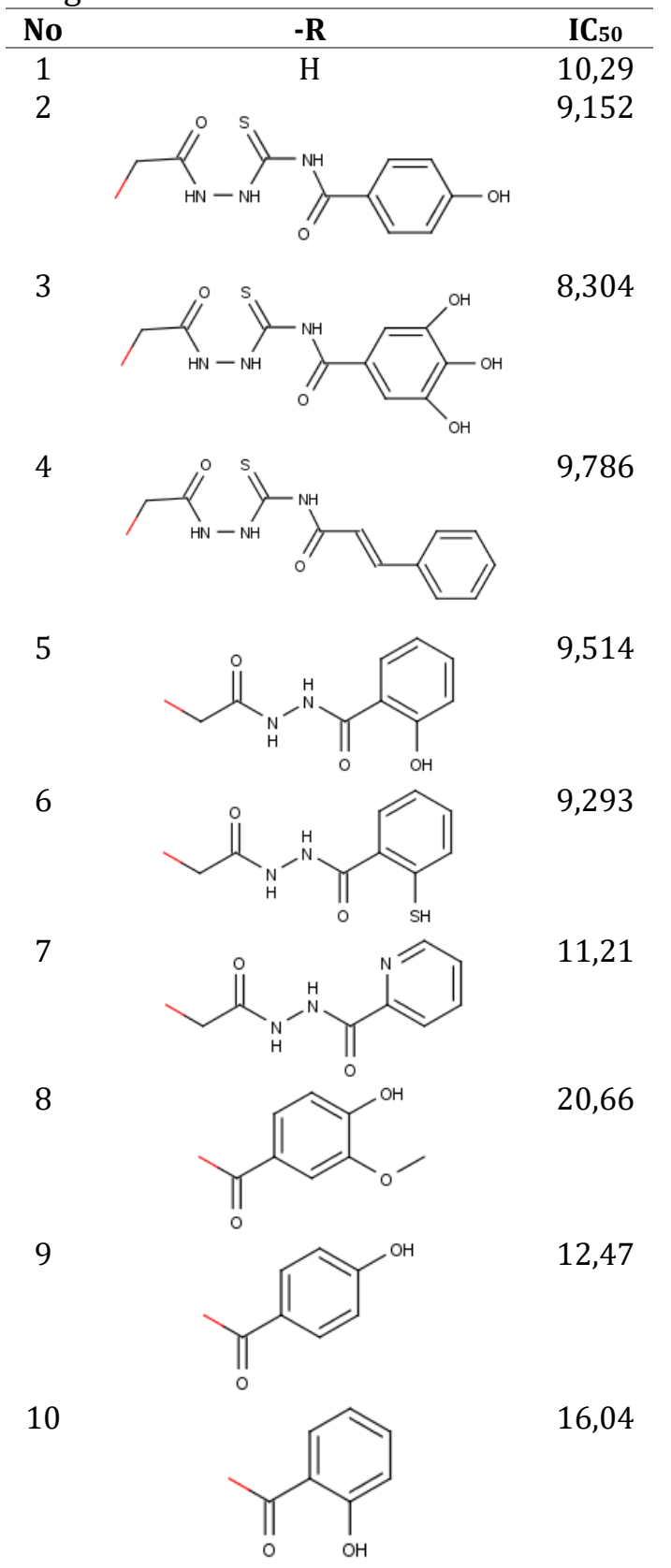

11<smiles>CC(=O)c1ccccc1S</smiles>

14,88

12<smiles>COc1cc(/C=C\C(C)=O)ccc1O</smiles>

13<smiles>CC(=O)/C=C\c1ccccc1</smiles>

31,3

Electronic descriptors and molecular descriptors were used in this calculation. The electronic descriptors used are the atomic charges. It is obtained by single-point calculations for all optimized compounds. The molecular descriptors used are HOMO energy, LUMO energy, Dipole Moment, Total Energy, Log P, Polarizability, Surface Area, and Hydration Energy. Molecular descriptors were also calculated using the QSAR Properties menu on all optimized compounds.

The obtained electronic and molecular descriptors were then correlated with the antioxidant activity of eugenol derivatives using multilinear regression analysis on BuildQSAR. The best equation was selected based on the statistical parameters R, s, F, Q2 , SPress, and SDep. Next, the equation is validated to remove outliers The QSAR equation model was used to predict the theoretical antioxidant activity of eugenol derivatives and predict new potential drugs from eugenol. Internal validations were used based on statistical parameters of the correlation between in vivo and in silico data (Veerasamy et al., 2011).

\section{Result and Discussion}

This study was conducted using data from previous studies. The modification of the group is shown in figure 2 . The molecular docking study of these modified eugenol 
derivatives has been shown to inhibit the activity of monoamine oxidase (MAO) which inhibits the oxidation process in the human body. The $\mathrm{IC}_{50}$ values of the structure were obtained through the determination of the DPPH radical scavenging activity of compounds $1-13$ as shown in table 1 (Dhiman et al., 2019). None of the research has studied the relationship between these structures and activities to predict new, more potent antioxidant compounds. Thus, this study aimed to investigate the relationship in the QSAR equation and predict the eugenol derivatives which have more potent antioxidant activity.

The material data used in this study are shown in Table 1 . following the experimental data of previous studies (Dhiman et al., 2019). The IC $_{50}$ value was changed in the form of a 1/C logarithm to indicate an increase in activity and the molecular structure of $1-13$ was represented in chemical descriptors. All molecules in Table 1 . were analyzed by the QSAR method.

The chemical descriptors used in this study follow the Hansch model (Kubinyi, 1997) namely electronic descriptors and lipophilic descriptors with the addition of topologic descriptors. In contrast to previous QSAR studies on eugenol derivatives (Wahab, 2013), this study focuses on net atomic charge descriptors because the net atomic charge data makes it easier to predict new compounds.

The use of the molecular descriptor HOMO - LUMO is based on the mechanism of radical scavenging by antioxidants. The electrons in HOMO are electrons that are ready to be given to radicals to turn them into unreactive molecules (Sohilait \& Kainama, 2019).

The calculated chemical descriptors were analyzed by using the build QSAR software to find the best equations. The indicator in determining the best equation is to use an R-value that is close to 1 . The analysis calculation produces the best equation as shown in Table 2.

The best equation in Table 2 . is equation 1 with a value of $R=0,961$. Equation 1 shows that 5 descriptors affect the activity of eugenol derivative compounds, namely the net charge of the C6, C-7 atoms, and hydration energy which has a negative coefficient and the net charge of the 0-12 atom and the energy of HOMO which has a positive coefficient.

The positive charge coefficients of the $\mathrm{C}-6$ and $\mathrm{C}-7$ atoms indicate that the more positive the atomic charge, the higher the value of the compound's activity. On the other hand, the net charge of the 0-12 atom needs to be decreased to increase the activity of the compound. The addition of electronwithdrawing groups on the C-6 and C-7 atoms results in the reduction of the electron density making the charge more positive so

Table 2. Results of QSAR equations

\begin{tabular}{|c|c|c|c|c|c|c|c|}
\hline No & Equation & $\mathbf{R}$ & $\mathbf{s}$ & $\mathbf{F}$ & $\mathbf{Q}^{2}$ & Spress & Sdep \\
\hline 1 & $\begin{array}{l}\log 1 / \mathrm{IC}_{50}=-4,4356( \pm 3,0432) \mathrm{qC} 6- \\
6,4807( \pm 6,1480) \mathrm{qC} 7+2,9295( \pm \\
6,2868) \mathrm{q0} 2+0,5158( \pm 0,4679) \\
\text { HOMO - 0,0062 }( \pm 0,0099) \text { hydration } \\
\text { energy }+3,6603( \pm 4,7868)\end{array}$ & 0,961 & 0,069 & 16,839 & 0,785 & 0,116 & 0,088 \\
\hline 2 & $\begin{array}{l}\log 1 / \mathrm{IC}_{50}=-6,9179( \pm 2,8506) \mathrm{qC} 6- \\
11,2766( \pm 6,6424) \mathrm{qC}+3,6733( \pm \\
3,7115) \mathrm{q} 010-3,0924( \pm 7,1507) \\
\text { q012 - 0,0050 }( \pm 0,0101) \text { hydration } \\
\text { energy - 1,5476 }( \pm 1,2082)\end{array}$ & 0,957 & 0,073 & 15,096 & 0,601 & 0,158 & 0,12 \\
\hline 3 & $\begin{array}{l}\log 1 / \mathrm{IC}_{50}=-6,4731( \pm 4,6997) \mathrm{qC} 6- \\
11,1949( \pm 9,0418) \mathrm{qC}+1,8135( \pm \\
6,8526) \mathrm{q010}-0,9393( \pm 12,0290) \\
\mathrm{q012}+0,2379( \pm 0,8862) \text { HOMO }+ \\
0,7726( \pm 8,9845)\end{array}$ & 0,951 & 0,077 & 13,196 & 0,691 & 0,139 & 0,106 \\
\hline
\end{tabular}


that their activity increases. Meanwhile, the addition of an electron-donating group on the $0-12$ atom will increase the electron density and also increase the activity value of the compound.

Equation 1 is validated with experimental data to analyze correlations and outliers. The activity correlation data from equation 1 is compared with the experiment. The result is shown in table 3 , where Y(obs) is the activity value of the experimental results and $Y$ (calc) is the calculated activity value. Outliers can be identified from the absolute value of Y(res). Value $\mid Y($ res $) \mid>2$. St.dev can be considered an outlier (Matysiak \& Niewiadomy, 2017). Thus, data for compound numbers 5, 8, and 9 can be omitted from the data set.

Table 3. Equation 1 validation

\begin{tabular}{cccc}
\hline Compound & Y (obs) & Y(calc) & Y(res) \\
\hline 1 & $-1,012$ & $-1,019$ & 0,007 \\
2 & $-0,962$ & $-0,925$ & $-0,037$ \\
3 & $-0,919$ & $-0,942$ & 0,023 \\
4 & $-0,991$ & $-0,97$ & $-0,021$ \\
5 & $-0,978$ & $-1,034$ & 0,056 \\
6 & $-0,968$ & $-0,956$ & $-0,012$ \\
7 & $-1,05$ & $-1,027$ & $-0,023$ \\
8 & $-1,315$ & $-1,203$ & $-0,112$ \\
9 & $-1,096$ & $-1,209$ & 0,114 \\
10 & $-1,205$ & $-1,222$ & 0,017 \\
11 & $-1,173$ & $-1,191$ & 0,018 \\
12 & $-1,442$ & $-1,409$ & $-0,034$ \\
13 & $-1,496$ & $-1,499$ & 0,003 \\
\hline Mean & $-1,12362$ & & \\
\hline Standard & 0,190474 & & \\
Deviation & & & \\
\hline
\end{tabular}

The new equation obtained after removing the outliers is as follows:

$\log 1 / \mathrm{IC}_{50}=-3,6148( \pm 1,7731) \mathrm{qC} 6-5,6898$ $( \pm 3,0640) \mathrm{qC} 7+3,2468( \pm 2,8421) \mathrm{q0} 12+$ 0,6643 ( \pm 0,2913) HOMO - 0,0070 ( \pm 0,0046) Hydration Energy $+5,0878 \pm \pm$ 2,8942)

$\mathrm{R}=0,996 ; \quad \mathrm{s}=0,026 ; \quad \mathrm{F}=108,78 ; \quad \mathrm{q} 2=0,902 ;$ Spress $=0,096 ;$ Sdep $=0,06$

This equation has a better $\mathrm{R}$-value of 0,996 . There is no standard deviation of each coefficient in this equation that exceeds its coefficient. Thus, this equation is the best QSAR equation for the eugenol data set and its derivatives.

The addition of substituents on C-6 and $0-12$ showed satisfactory results. The three predictive drug compounds have predicted $\mathrm{IC}_{50}$ values below 5 . This activity value is better than the $\mathrm{IC}_{50}$ value of ascorbic acid as an antioxidant standard (Dhiman et al., 2019). The $-\mathrm{NH}_{2}$ group as an electrondonating group and a benzene group as an electron-withdrawing group is the best combination of additional groups with a predicted $\mathrm{IC}_{50}$ value of $3,231516 \mathrm{~g} / \mathrm{mL}$. This is because it has a strong affinity for donating electron density towards the C- 6 atom and the benzene group with its electron resonance that can attract electron density from 0-12. Thus, the development of eugenol derivative compounds as antioxidants is very appropriate to do.

Table 4. Proposed modification of new compounds derived from eugenol

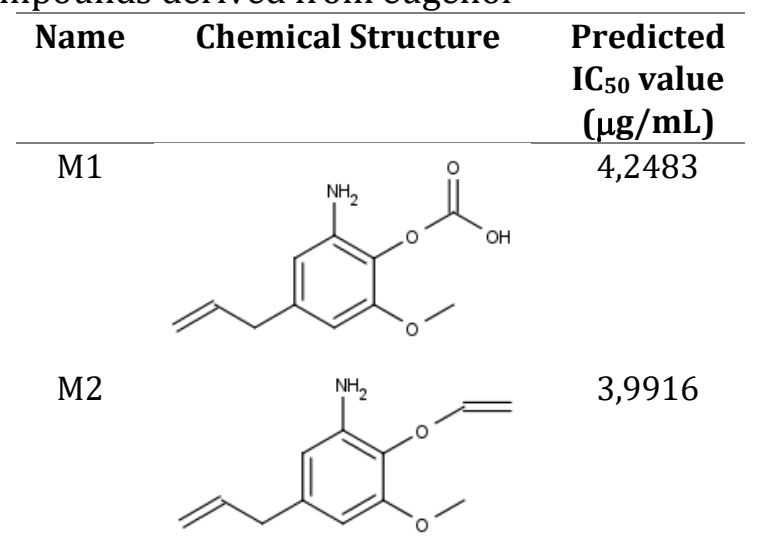


M3

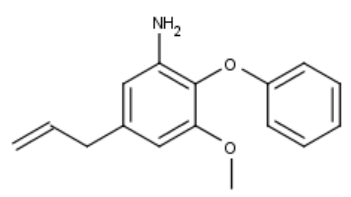

3,2315

\section{Conclusion}

The electronic and molecular electronic descriptors of eugenol derivatives, namely net charge of C-6, C-7, 0-12 atoms, HOMO energy, and hydration energy have a significant effect on antioxidant activity as shown by the best QSAR equation:

$$
\log 1 / \mathrm{IC}_{50}=-3,6148( \pm 1,7731) \mathrm{qC} 6-
$$

$5,6898( \pm 3,0640) \mathrm{qC7}+3,2468( \pm 2,8421)$ q012 + 0,6643 ( $\pm 0,2913)$ HOMO - $0,0070( \pm$ $0,0046)$ Hydration Energy $+5,0878( \pm$ 2,8942)

The addition of an electron-donating group at C-6 and an electron-withdrawing group at 0-12 gave a better prediction of the $\mathrm{IC}_{50}$ activity value than eugenol and ascorbic acid with the best predictive $\mathrm{IC}_{50}$ value of $3,231516 \mathrm{~g} / \mathrm{mL}$.

Further research to explore eugenol derivatives through in silico, in vitro, and in vivo studies needs to be carried out continuously to find new antioxidant drug compounds.

\section{Acknowledgment}

The authors would like to thank the Austrian -Indonesian Center for Computational Chemistry of Universitas Gadjah Mada for supporting this research.

\section{Reference}

Amanda, K. A., Mustofa, S., \& Nasution, S. H. (2019). Review Efek Antioksidan pada Kemuning ( Murraya paniculata ( L .) Jack ). Majority, 8(2), 265-272.

Arifin, B., \& Ibrahim, S. (2018). Struktur, Bioaktivitas Dan Antioksidan Flavonoid. Jurnal Zarah, 6(1), 21-29. https://doi.org/10.31629/zarah.v6i1. 313

Cortes, E., Mora, J., \& Márquez, E. (2020). Modelling the anti-methicillin-resistant staphylococcus aureus (MRSA) activity of cannabinoids: A QSAR and docking study. Crystals, 10(8), 1-20. https://doi.org/10.3390/cryst100806 92

De Oliveira, D. B., \& Gaudio, A. C. (2001). BuildQSAR: A new computer program for QSAR analysis. Quantitative Structure-Activity Relationships, 19(6), 599-601.

https://doi.org/10.1002/1521-

3838(200012)19:6<599::AID-

QSAR599>3.0.CO;2-B

Da Silva, F. F. M., Monte, F. J. Q., de Lemos, T. L. G., do Nascimento, P. G. G., de Medeiros Costa, A. K., \& de Paiva, L. M. M. (2018). Eugenol derivatives: synthesis, characterization, and evaluation of antibacterial and antioxidant activities. Chemistry Central Journal, 12(1), 1-9. https://doi.org/10.1186/s13065-0180407-4

Dhiman, P., Malik, N., \& Khatkar, A. (2019). Lead optimization for promising monoamine oxidase inhibitor from eugenol for the treatment of neurological disorder: Synthesis and in silico based study. BMC Chemistry, 13(3), 1-20. https://doi.org/10.1186/s13065-0190552-4

Hanifa, D., \& Susilawati, Y. (2017). Potensi Tanaman Gandaria (Bouea Macrophylla Griff) Sebagai Obat Herbal Yang Beraktivitas Antioksidan. Farmaka, 15(Vol 15, No 3 (2017): Farmaka), 134-142. http://jurnal.unpad.ac.id/farmaka/arti cle/view/13559

Hussain, Z., Thu, H. E., Amjad, M. W., Hussain, F., Ahmed, T. A., \& Khan, S. (2017). Exploring recent developments to 
improve antioxidant, antiinflammatory and antimicrobial efficacy of curcumin: A review of new trends and future perspectives. Materials Science and Engineering C, 77(November), 1316-1326. https://doi.org/10.1016/j.msec.2017. 03.226

Julianus Sohilait, H., \& Kainama, H. (2019). Free Radical Scavenging Activity of Essential Oil of Eugenia caryophylata from Amboina Island and Derivatives of Eugenol. Open Chemistry, 17(1), 422-428.

https://doi.org/10.1515/chem-20190047

Kubinyi, H. (1997). QSAR and 3D QSAR in drug design. Part 1: Methodology. Drug Discovery Today, 2(11), 457-467. https://doi.org/10.1016/S13596446(97)01079-9

Matysiak, J., \& Niewiadomy, A. (2017). QSAR models of antiproliferative activity of imidazo[2,1-b] $[1,3,4]$ thiadiazoles in various cancer cell lines. Molecular Diversity, 21(1), 211-218. https://doi.org/10.1007/s11030-0169705-8

Muhammad Rashidi Wahab, M. F. A. (2013). Jurnal Teknologi. Jurnal Teknologi, 7, 31-39.
Mumpuni, E., \& Mulatsari, E. (2017). QSAR analysis on apigenin derivative compounds as antioxidant using semiempirical austin model 1. Asian Journal of Chemistry, 29(7), 14991505.

https://doi.org/10.14233/ajchem.201 7.20535

Ribaudo, G., Bortoli, M., Pavan, C., Zagotto, G., \& Orian, L. (2020). Antioxidant potential of psychotropic drugs: From clinical evidence to in vitro and in vivo assessment and toward a new challenge for in silico molecular design. Antioxidants, $\quad 9(8), \quad 1-22$. https://doi.org/10.3390/antiox90807 14

Veerasamy, R., Rajak, H., Jain, A., Sivadasan, S., Varghese, C. P., \& Agrawal, R. K. (2011). Validation of QSAR Models Strategies and Importance. International Journal of Drug Design and Disocovery, 2(3), 511-519 
Attachment 1. Tabel of Descriptors Calculated from Eugenol \& Its Derivatives

\begin{tabular}{|c|c|}
\hline 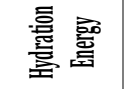 & 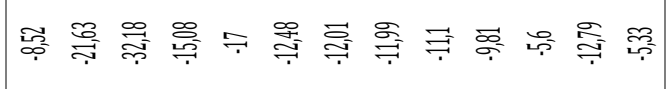 \\
\hline 蒡森 & 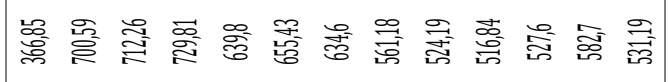 \\
\hline 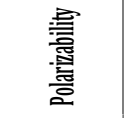 & 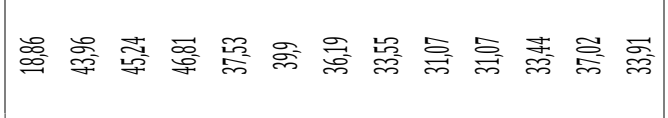 \\
\hline 愙 & 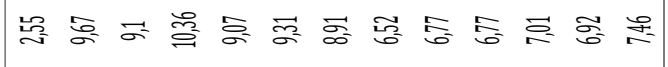 \\
\hline 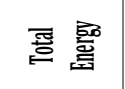 & 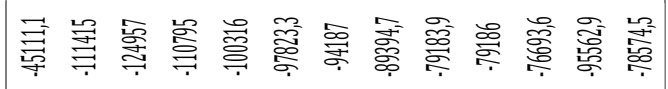 \\
\hline 总言 & 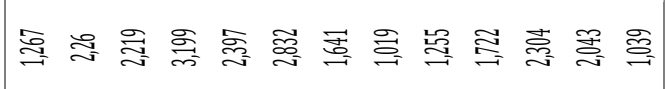 \\
\hline & 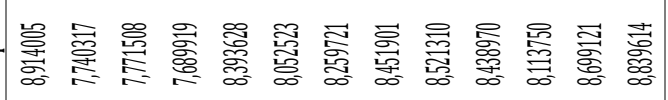 \\
\hline 产 & 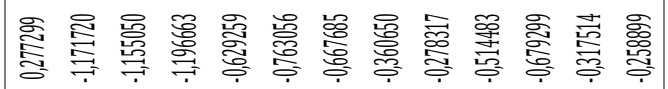 \\
\hline 产 & 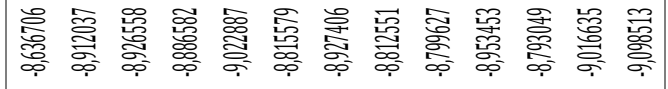 \\
\hline పे & 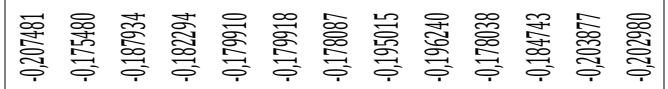 \\
\hline $\bar{z}$ & 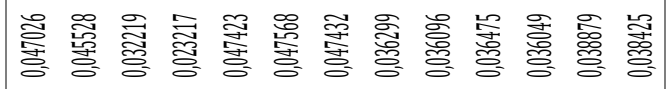 \\
\hline & 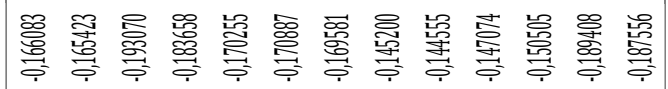 \\
\hline & 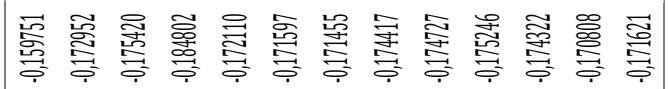 \\
\hline & 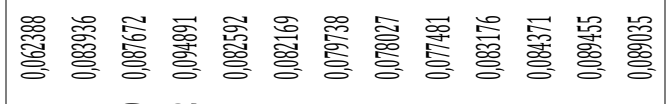 \\
\hline & 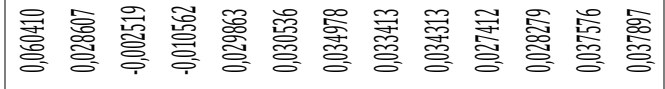 \\
\hline & 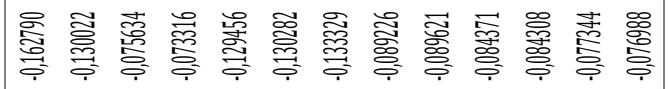 \\
\hline & 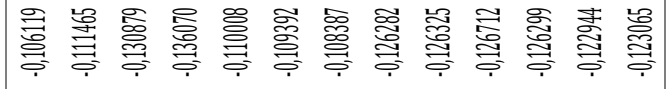 \\
\hline & 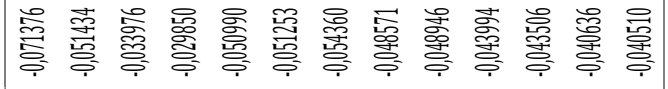 \\
\hline & 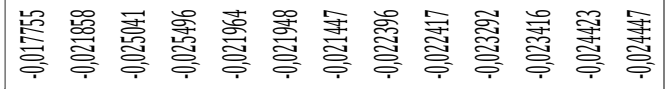 \\
\hline & 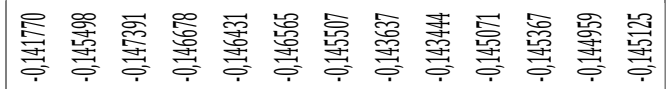 \\
\hline & 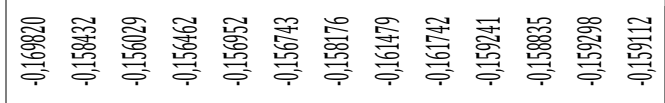 \\
\hline & $-\sim m+r$ \\
\hline
\end{tabular}

